\title{
Italia en los TeXtos de Ramón Gaya: EPISTOLARIO Y ESCRITOS
}

\author{
Pedro Luis Ladrón de Guevara \\ Universidad de Murcia
}

\section{RESUMEN:}

Ramón Gaya fijó su residencia en Italia tras un viaje a Europa en el verano de 1952. El deslumbramiento por Venecia, la presencia creciente de escritores españoles que volvían del exilio americano y la acogida en Roma de los círculos literarios italianos propició que Italia fuese el país de elección para el pintor. En este artículo se recorre la huella de Italia en el epistolario y los escritos de Gaya.

Palabras clave:

Ramón Gaya, Viaje a Italia, Elena Croce, Cristina Campo.
AbStract:

Ramón Gaya settled in Italy after a trip to Europe in the summer of 1952. The dazzling of Venice, the growing presence of Spanish writers returning from American exile and the reception in Rome of Italian literary circles led to Italy being the country of choice for the painter. This article traces the footprint of Italy in Gaya's letters and writings.

KEY WORDS:

Ramón Gaya, Grand Tour, Elena Croce, Cristina Campo.

El pintor y ensayista Ramón Gaya visita Italia por primera vez en junio de 1952, con 42 años, proveniente de México. Permanecería en Europa hasta junio de 1953. Aquel verano de 1952 realiza un viaje con Clara James, Concha de Albornoz y Juan Gil-Albert por Venecia, Padua, Vicenza, Verona, Florencia, Roma, Nápoles, Pestum, la Costa Amalfitana... Los planes para el viaje se los cuenta Gaya a Salvador Moreno, desde la casa de Julián Calvo, el 21 de mayo:

El 15 de julio Concha saldrá en coche (en el coche de una amiga) hacia Austria y, pasando velozmente por Viena, llegará el 25 de julio a Venecia. Yo, seguramente, estaré desde el 16 o 17 allí, en Venecia, adonde llegará también Juan el 22 o 23 de julio. Tendré, pues, 
unos días venecianos de soledad absoluta. Estaremos en Venecia hasta el 31 de julio, en que saldríamos para Florencia; estaremos en Florencia (haciendo excursiones en el auto de Clarita a Siena y Asís) alrededor de una semana, al cabo de la cual nos encaminaremos a Roma; estaremos, pues, en Roma desde el día siete, 8 ó 9 de agosto, unas dos semanas, o sea, que hacia el 20 de agosto nos encontraremos en Nápoles, Pestum, Pompeya (Gaya, 2016: 229-230) $)^{1}$.

Años más tarde, el 21 de agosto de 1955, Ramón le recordaría ese viaje a Clara James, contándole además sus planes para establecerse en Florencia, aunque en realidad la ciudad elegida finalmente sería Roma:

Querida Clarita: ¿Te acuerdas de nuestro baño? ¡Qué días aquellos! ¿Cuándo repetimos? Yo pienso ir a Italia hacia enero de 1956 -si el tiempo lo permite-, con la idea de instalarme en Florencia por un año por lo menos -quizá dos-. De esta charca para coches ya estoy hasta los pelos (de arriba). He aguantado todo este tiempo para poder asegurarme cuatro o cinco años en Europa, y creo que voy camino de lograrlo (Zambrano-Gaya, 2018: 30).

De aquel viaje surgen sus principales impresiones sobre las ciudades que visita. Lleva por título Cuaderno de viaje y fue publicado en México por Mazapanes Toledo como calendario de 1953. Además de algunas ciudades francesas, recoge impresiones sobre Roma, Siena, Venecia, Asís, Pisa, Florencia, Pompeya y Pestum. Para Gaya,

apenas entramos en Roma nos damos cuenta de que lo redondo, la perfección limitada de lo redondo, es su clave [...]. Roma halaga en nosotros toda nuestra terrenalidad, disculpa nuestra terrenalidad [...]. Roma es, en efecto, eterna, pero no como es eterno el espíritu, sino como es eterna la tierra, como es eterno el suelo firme, nuestro suelo, el suelo de la vida (Gaya, 2010: 335).

Para él, «el arte no es otra cosa, no puede ser otra cosa que vida, carne viva, aunque, claro, no sea nunca mundo» (Gaya, 2010: 32), lo que hace de Siena una ciudad de arte, pues Siena es toda de carne, donde el Renacimiento pareció pasar de largo, donde «parece expresar el otro rostro vivo de la Edad Media: una especie de alegría, de sensualidad recia y sana, de festividad inocente», y alude a la santa de la ciudad, Santa Catalina: «una de esas naturalezas privilegiadas -como la de Nietzsche-, en donde lo decisivo no es nunca aquello que dicen, sino aquello que

\footnotetext{
${ }^{1}$ En realidad, la ciudad elegida no fue Florencia sino Roma, quizá por ser más barata. Para un amplio estudio, véase José Luis Valcárcel Pérez (2010: 153-168, 183-235).
} 
están viendo cuando nos dicen algo», para reafirmar que «ellos son verdad» (2010: 336).

Venecia es la ciudad sobre la que más escribirá en su prosa literaria y en sus cartas:

Con prisa, sin un orden riguroso, se le fueron añadiendo ingredientes muy distintos, como en un guiso, y salpicándolo luego de muchas especias orientales, dejaron que todo se cociese a la luz transfiguradora del Adriático; luz mágica, eso sí, aparentemente débil y fría, pero que supo convertir el mármol en nube, la piedra en agua, y reducirlo todo a una especie de materia tornasol. Esta materia tornasol, es decir, compleja, es lo que verdaderamente puede llamarse el milagro vivo de lo veneciano (Gaya, 2010: 338).

Y escribe al amigo Tomás Segovia el 14 de julio:

Todo esto es de una belleza extraña. No tiene, apenas, nada que ver con las fotos que conocemos ¡Cuánta vida! Contra todo lo que se suele decir, Venezia, no es nada museo. Todos estos museos bizantinos, góticos, renacentistas, que tan marcados, duros y artificiales, vemos en las fotos, aquí están como disimulados en la realidad, fundidos en ella. Ahora recuerdo que Corpus Barga me había dicho que la luz del Adriático era única, y es cierto; es una luz que en el transcurso de un cuarto de hora puede hacer que aparezca y desaparezca toda la ciudad (Gaya, 2016: 244-245).

Venecia es agua que todo lo diluye, pero también es la fuente de la que emana la pintura. Por eso, para él, en Sentimiento de la pintura, de 1959, Tiziano, máximo exponente de la pintura, veneciana o no, junto con Velázquez, «casi no es un pintor, sino pintura, es decir, logra ser impersonal a fuerza de ser sentimiento solo, sentimiento pictórico absoluto», y añade:

Mientras tanto callejeaba por el apretado laberinto de Venecia, deteniéndome en cada uno de esos puentes casi chinos, entre útiles y caprichosos, en los cuales pasaba horas inmóvil, emocionado pero inmóvil como una tortuga, absorbiendo rareza, belleza, pringosidad, o sea, mojándome en el aceitoso veneno de estas calles, de un realismo tan inverosímil. Un atardecer, de entre aquellas aguas espesas, usadas, me pareció ver salir, surgir como una Venus cochambrosa, el manchado cuerpo de la Pintura (Gaya, 2010: 41, 43).

Verona le parece «indescriptible», «una de las más hermosas ciudades que se puedan ver». Así se lo cuenta por carta a Teresa de la Serna el 26 de julio. Le confiesa su asombro, a pesar de las altas expectativas que tenía de Italia: 
Verona es de verse y no creerse. Verona es muy completa, con plazas inimaginables, iglesias del siglo VIII, tumbas románicas por las calles, palacios medievales, gente guapa - iy actual!- que no desentona, restos romanos, Tizianos, Veroneses en casi todas las iglesias, un empedrado de losas grandes unas veces y otras de canto rodado desgastado que le da una consistencia, una fijeza enorme a toda la ciudad. Esperaba mucho de Italia, pero no tanto. Estoy asombrado, y casi asustado, pues después no sé dónde se puede uno quedar (Gaya, 2016: 259).

De la ciudad de Asís destaca su carácter medieval y, al igual que hiciera con Siena, la relación con el santo: «Nos encontramos, de pronto, en una Edad Media presente, actual, nada histórica [...]. La fachada del Duomo, como de hierro, es una de las superficies más hermosas y ricas que se pueden ver»; y del santo destaca: «en San Francisco no hay nunca paisaje, porque todos aquellos elementos que podían formarlo los ha convertido ya, milagrosamente, en seres, en hermanos suyos, es decir, en dignos de misericordia» (2010: 341-342).

De Pisa recordará la Piazza dei Miracoli, con la torre, el baptisterio, el campo santo (cementerio) y el Duomo. Espacio vivo, actual: «las piedras y las líneas eran, sí, románicas, pero todas sus leyes, reunidas en aquel lugar como en un nido, estaban sin embargo, en vigencia, tenían palpitación, eran presente»; por eso, al irse no puede dejar de reflexionar: «contemplé una vez más todo aquel conjunto de mármoles prodigiosamente ligeros $\mathrm{y}$, de pronto, vi con claridad que lo que realmente había anidado en aquella blandura era la Geometría misma» (2010: 343).

Y de Florencia, de esa ciudad en la que también le hubiera gustado vivir, que procura visitar con cierta asiduidad, resalta su esplendor de «un gran patio señorial, sonoro de castillo recio [...]. Irse de una ciudad como Florencia es, pues, difícil, no por encerrar más bellezas que otras, sino porque la Belleza y el Arte -que parecen representar siempre una como separación de la vida- tiene allí ese carácter único de fiesta cotidiana, de fiesta de patio, casi de corral» (2010: 344, 345). Al pasear desde Fiesole a Florencia recuerda las ciudades vistas y confiesa: «Todo es tan hermoso que parece mentira» (2016: 265).

$\mathrm{Su}$ admiración por las ruinas es palpable en sus visitas constantes a los Foros Romanos, donde iría a pintar mientras vivió en Roma, pero ya desde su llegada le atraen: la visita a Pompeya, la ciudad destruida catastróficamente no le procura tristeza, sino que le impresiona. Allí no solo contempla las tabernas, el empedrado, las aceras que nos han llegado «con una extraña actualidad, con una actualidad que yo llamaría traidora, demoniaca», sino que se detiene en las pinturas aparentemente solo decorativas, hechas por artesanos, pero donde comprende que algunas van más 
allá, «están allí no solo con frescor, con un frescor conservado, sino llenas de una modernidad resistente, consistente, loca» (2010: 346).

También admira Pestum, en la Campania, cuya capital es Nápoles, perteneciente a la Magna Grecia, y por tanto más griega que romana, con sus admirables templos:

En pocos lugares he sentido como aquí, en este mendrugo de lo griego, una emoción tan difícil, tan compleja, de solemnidad y mendicidad mezcladas. Aquellos templos me parecieron tres mendigos majestuosos, sabios [...]; comprendí entonces algo que ya sentía desde antes: que en lo griego hay mucho más cristianismo que en lo egipcio y lo romano, posiblemente por su absoluta falta de soberbia, de enemistad, de terquedad materialista (Gaya, 2010: 352).

En sus cartas aparecen ciudades como Ostia Antica, el antiguo puerto romano: increíble «de belleza y de encantamiento, está casi intacto el trazado de la ciudad y las ruinas de los templos, estatuas en pie, el teatro (maravilloso), las calles de las tiendas, y uno puede pensar en San Agustín andando por allí» (2016: 267). Perusa, «Perugia es preciosa también» (2016: 267). Ésta es la impresión que tiene Ramón Gaya de Italia, esto es lo que le atrae y le hará elegirla como su residencia, no la París de la vanguardia pictórica, sino la Italia de Tiziano, Tintoretto, Miguel Ángel... «Italia, en definitiva, es eso: un atrevimiento», llega a decir (2018: 30).

Ramón Gaya y María Zambrano ya habían manifestado su interés por ir a Italia hacía años. El 29 de abril de 1949, desde La Habana, María le escribe a Jorge Guillén: «Ahora quería ir a Europa. A Italia un año» (Zambrano-Gaya, 2018: 22)2, y también al propio Gaya, el 13 de junio de aquel mismo año: «Yo me marcho con Araceli [su hermana], claro está, a Italia y a Francia. No sé bien cómo, pues si lo supiera no lo haría y hay que hacerlo así, sin saberlo bien. Voy a correr un riesgo, pero ¿cuándo no? Salimos de aquí el día 12 de julio en barco. Escríbeme antes, por favor» (Zambrano-Gaya, 2018: 25).

En la respuesta, del 24 de junio, Gaya le muestra su interés por Italia:

Te envidio mucho lo de Italia. Escríbeme desde allí, no dejes de hacerlo; no me abandones como todo este tiempo de La Habana. Me atrae mucho, otra vez, Venecia. Creo que ya la vería con todo lo que debe tener de cochambroso delicado, de cristal sucio, de perla usada. No dejes de escribirme desde Italia, dándome detalles de precios y todo (Zambrano-Gaya, 2018: 28).

\footnotetext{
${ }^{2}$ María Zambrano-Ramón Gaya (2018: 22). Archivo Jorge Guillén, Biblioteca Nacional de España, $\mathrm{JG} / 102 / 5$.
} 
Curioso este otra vez, que no implica vuelta a un lugar, pues nunca ha estado, tal y como se desprende del uso del condicional referido a la visión que le produciría la ciudad de los canales, sino a su previsible reacción ante la visión de una ciudad soñada y ensoñada.

Gaya volvió a México en junio de 1953. Trabajó con ahínco con la finalidad de ahorrar y poder volver a Europa. En 1956 vende toda la obra que tiene, la mayor parte a un único comprador, y con el dinero obtenido proyecta mantenerse modestamente durante algunos años en Europa. Va a Roma, donde vive su amiga María Zambrano, que ya se había instalado allí, amiga también y compañera de su primera mujer, $\mathrm{Fe}$ Sanz, la madre de su hija Alicia (Zambrano, 2002: 116). Ya el 8 de agosto de 1952 le había manifestado por carta a Tomás Segovia: «No te imaginas lo que es Roma; es, quizá, la ciudad para vivir en ella años y años seguidos» (Gaya, 2016: 265). En Roma, María le abre las puertas de su casa y de la de Elena Croce ${ }^{3}$ (Colinas, 2019: 283-284), hija del famoso crítico napolitano Benedetto Croce, lugar de reuniones literarias.

Gaya, en general, será reticente a la vida social y algo mundana de los círculos intelectuales; de hecho, no se conoce que estableciera ningún contacto con los de Venecia o Florencia, ni con otros grupos de Roma. Pensemos en el círculo romano de Maria Bellonci, escritora y fundadora, junto a su marido Goffredo, del Premio Strega, no cita en sus memorias a casi ninguno de los asiduos a la casa de Elena Croce ${ }^{4}$.

No fue en Florencia, donde había pensado inicialmente, ni tampoco en Venecia, quizás demasiado caras, donde se instala Ramón Gaya, sino en Roma ${ }^{5}$. En esta ciudad tendría estudio durante las siguientes tres décadas. Conoce a Elena Croce, al escultor Giacomo Manzù («gran escultor, mejor que todos los demás contemporáneos»), Elémire Zolla, Cristina Campo ${ }^{6}$, Pietro Citati, Niccolà Chiaromonte, Italo Calvino,

\footnotetext{
${ }^{3}$ Según Antonio Colinas, fue Diego de Mesa, alumno de María en el Instituto Escuela de Madrid y residente en Roma como traductor en la FAO, el que puso en contacto a María con Elena Croce.

${ }^{4}$ Excepto a Elémire Zolla, que ganó el premio por su ópera prima: «Aquel 1956, décimo Premio Strega, con Guido Alberti, siempre atento a los jóvenes, pensamos en dar también un premio a una ópera prima que tuvo este carácter original: el jurado estaría formado por vencedores del Strega. Ganó Elémire Zolla con su primera novela Minuetto all'inferno, libro que sorprendió a todos, oscilante entre una especie de realismo mágico y un moderno racionalismo» (Bellonci, 1971: 52-53).

${ }^{5}$ El 18 de abril de 1958 Gaya le escribía a Salvador Moreno, aunque pensando en una corta visita de éste: «Firenze es, quizá, un poco más barato que Roma, y desde luego más barato que la Serenísima, de la cual tengo una nostalgia terrible. Pero otra vez será» (2016: 543). Gaya siempre concibió el estudiocasa. Hijo único, desde muy pequeño su madre le dejaba pintar en la habitación principal de la casa, por lo que se acostumbró a pintar en medio de la actividad normal de la vivienda. Tuvo cuatro casasestudios: en Via Margutta (1956-1957), en Via Mario de' Fiori (1957-1963), en Via del Babuino (19631970) y en la que adquirió -hablan de ello Elena Croce y María Zambrano en sus cartas- en Vicolo del Giglio (1970-2005). Véase Las casas del pintor. Estudios de Ramón Gaya (Museo Ramón Gaya, 2014).

${ }^{6}$ Sobre Cristina Campo y Ramón Gaya, así como con Jorge Guillén y María Zambrano, véase Pedro Luis Ladrón de Guevara, «Cristina Campo y su tiempo», en Cristina De Stefano (2020: 9-26).
} 
Italia en los textos de Ramón Gaya: Epistolario y escritos

Carlo Levi, Lionello Venturi... Elena tenía una tertulia cultural en su casa, en el prestigioso barrio de Parioli ${ }^{7}$, en Via Tre Madonne 16, donde siempre fueron bien acogidos los españoles. Allí asistían poetas como Jorge Guillén, pensadores como María Zambrano, y Ramón Gaya como pintor y crítico. En Roma retomaron y reforzaron su amistad, tras el período de la II República y el exilio en América, María y Ramón. Además, Elena le ayudaría a vender muchos de sus cuadros.

De aquellos años romanos escribiría Ramón el 23 de abril de 1989, en el diario $\mathrm{ABC}$, con motivo de la concesión a la escritora del Premio Cervantes:

En Roma, durante años, nos hemos visto casi todos los días. Yo tenía entonces un estudio en Mario di Fiori, casi esquina a Via Condotti, y María, con su hermana Araceli, vivía en Piazza del Popolo. Nos movíamos muy bien por estos lugares: el café Greco, Piazza di Spagna, Via del Babuino, la frutería, la trattoria; el lujosísimo escaparate de ropa o de joyas al lado mismo del verdulero, los gatos... Pero quizá en donde he visto a María, no más feliz, ni más triste, sino más... plena, más completa, ha sido en la Via Apia. A María le gustaba, sobre todo, llegar hasta un relieve muy perdido, muy gastado, de una tumba romana (Zambrano-Gaya, 2018: 235).

Gaya acompañaría el texto con un dibujo donde aparecían ambos en la Via Appia frente a la tumba.

Pero no solo se reúnen en casa de Elena Croce, a veces lo hacen en la de María y Araceli Zambrano. María le escribe un tarjetón el martes 26 (quizá junio de 1956) para una reunión con unos amigos y presentarles a Ramón. Le ruega discreción:

Me alegraría muchísimo que mañana miércoles 27 puedas venir a casa a las 7 de la tarde. Viene Elena, y dos amigos italianos, gente interesante. Les he dicho de ti y quisieran conocerte. Espero te sea grato.

Te suplico, por causas obvias y otras que te diré, que nada digas a nadie, incluso [a] la persona que suele estar con nosotros tres. Por algo lo digo (Zambrano-Gaya, 2018: $32-33)$.

El 3 de diciembre Ramón le escribe a María desde París. En su viaje había pasado por Milán, donde pernoctó unos días, y a la vuelta pensaba acabar en Venecia, ciudad en la que le gusta estar en soledad, en contacto con sus aguas y la pintura: «Estuve en Milán tres días, donde vi dos museos que no había visto. Hasta el 20 estaré aquí [París], y después volveré a Milano unos días, y quizá pase la Navidad en Venezia, solo, como un fungo [una seta]» (Zambrano-Gaya, 2018: 39).

\footnotetext{
${ }^{7}$ El poeta Enrique de Rivas, fallecido mientras redacto estas líneas, hijo de Cipriano Rivas Cherif y sobrino de Manuel Azaña, escribe a María Zambrano: «fuiste tú quien me presentó a Elémire y fue también estando contigo cuando conocí a Vittoria, en casa de Elena en Parioli» (Campo, 2014: 14).
} 
María no sabía que se había ido a París, lo buscaba incesantemente. Había leído su artículo «El silencio del arte», publicado años antes en Cuadernos Americanos (México, LV, n. ${ }^{\circ}$, enero-febrero 1951, páginas 122-137) y quería expresarle su maravilla. Además, le aconseja que vaya a ver al, por entonces poco conocido, escritor rumano que publica en francés, Emil Cioran (Hotel Marjory, 20 Rue de M. le Prince), que adora España ${ }^{8}$. María busca a Ramón en el café Greco:

Fui a buscarte al Greco: te había llamado varias veces, pero atribuí el vacío de tu casa, ese no estar la persona que a través del teléfono se siente, a que andabas por ahí pescando, de bureo [...]. El camarero que te sirve -te sirve de verdad-me dijo con aire dolido que ya no ibas por allá; después otros días me miró huidizo como quien teme algo de una mujer «così insistenti», aunque yo iba a tomar café nada más; al fin le dije que estás fuera para que me restituyera la confianza (Zambrano-Gaya, 2018: 41).

A la vuelta del viaje de París, permanece en la Serenissima, la amada Venecia, la ciudad que siente suya y donde se siente pleno, sereno, en contraposición a Roma, lugar de trabajo, aunque él nunca deja de pintar. El 8 de enero de 1957 escribe:

María: un abrazo desde mi ciudad, que me produce siempre una rara exaltación de serenidad, de estado completo. Dentro de unos días volveré a Roma, donde me meteré en el trabajo, como en una cueva, para aprovechar estos meses que me quedan de "estudio". Después, intentaré encontrar estudio en Venezia, decididamente (Zambrano-Gaya, 2018: 45-46).

Es evidente que de encontrar alojamiento en Venecia no tuvo carácter definitivo El 2 de junio de 1957 Gaya le escribe desde Florencia, con una tarjeta postal que recoge L'adorazione dei Magi. Le cuenta sus cuitas: al volver a Roma tuvo que cambiar de casa, pues la vuelta de los propietarios del estudio de Via Marguta le obligaba a buscar uno nuevo. Con María volvió a la capital toscana en octubre y desde allí escriben al común amigo Juan Gil-Albert: «María también está aquí, donde se quedará, por lo visto, unas semanas más, para trabajar en un libro que le ronda. Esto está precioso en este momento, pero tengo ganas de llegar a mi estudio de Roma y ver de trabajar con algo de más cuerpo» (Zambrano-Gaya, 2018: 55).

La pasión por la soledad necesaria para trabajar, para pensar, para ser, se evidencia en la carta que escribe a finales de aquel año a Juan Gil-Albert:

\footnotetext{
${ }^{8}$ En la biblioteca de María Zambrano se encuentran los siguientes libros de Cioran: De l'inconvénient d'être né (con dedicatoria), Précis de décomposition y Esercizi di ammirazione.
} 
En Firenze he pintado bastante, y creo que bien, o por lo menos, aprovechable. La ciudad estaba, con el otoño, preciosa. No te puedes imaginar (o mejor, sí, puedes imaginar) esas lomas y cerros alrededor, con los verdes transformados por el otoño, en hierro viejo finísimo, malvas negros, rosa uva.

María estuvo en Firenze unos diez o doce días, trabajando en un libro que parece verdaderamente magnífico (aunque yo solo conozco algunas páginas preparativas) y lo pasamos bastante bien, pues hacíamos vida aparte, viéndonos únicamente para comer y cenar; este régimen nos permitió acompañarnos sin quitarnos soledad, la soledad que se necesita para hacer lo que uno quiere hacer (Gaya, 2016: 523).

Sobre las obras que pintó en Italia el propio Ramón confiesa a Elena Aub desconocer la cantidad («Yo soy sumamente descuidado, tengo algunas fotografías, desde luego, pero desordenadamente, ni siquiera de los mejores cuadros. Si algún día quieren hacer una revisión de mis cosas van a tener mucho trabajo») (Aub, 2007: 194). Pongamos, a modo de ejemplo, algunas de sus pinturas hechas en y sobre Italia: de 1952 son Atardecer en el foro (gouache 25 x 33), Cava de Tirreno (gouache 35 x 24); de 1953 son los dedicados a Venecia Café Florian (pastel sobre papel 21 x $37 \mathrm{~cm}$ ), Puente de la Academia con lluvia (gouache sobre papel 27 x $20 \mathrm{~cm}$ ), La piazzetta (San Marco y el Ducale) (gouache sobre papel 27 x $36 \mathrm{~cm}$ ), Atardecer en Venecia (gouache sobre papel 29 x $25 \mathrm{~cm}$ ); de 1956 son en Roma El Coliseo (gouache sobre papel 39 x $50 \mathrm{~cm}$ ), El foro con lluvia (gouache sobre papel 39 × 50 $\mathrm{cm}$ ), Atardecer romano (gouache sobre papel $49 \times 35 \mathrm{~cm}$ ), El foro con figura. Roma (pastel sobre papel 22 x 29); de 1957 Florencia (acuarela sobre papel 49 x 64), Firenze desde el Boboli (pastel sobre papel 24 x 30); Arco de Tito (pastel sobre papel 23 x 30); de 1958 son El Palatino (gouache sobre papel 48 x 63), también la visión nocturna del Arno, Las luces del Ponte Vecchio (gouaches obre papel 23 x $29 \mathrm{~cm}$ ) y El Arno (pastel sobre papel 23 x $30 \mathrm{~cm}$ ); de 1966 es Mi terraza de Roma (gouache sobre papel 70 x $100 \mathrm{~cm}$ ); de 1971 Los baños del Tevere (gouache sobre papel 48 x 62); de 1981 Venecia. El atardecer reflejado en el cristal de la ventana (óleo sobre lienzo 60 x 40), etc. Ramón quiere pintar las ruinas más escondidas, aunque también los sitios más conocidos y turísticos, por la belleza que contienen y sin prejuicios ${ }^{9}$.

La fascinación por Venecia se repite en otras de sus cartas. Roma es la vida y su trabajo, Florencia, son los colores y el pintar, Venecia es ritmo ácueo donde la presencia de turistas no es nada comparado con la ausencia de coches, motos, estruendos. Venecia, al fin y a la postre, es una ciudad silenciosa.

\footnotetext{
${ }^{9}$ Sobre Roma, Venecia y Florencia véase «Solo, pero no de espaldas (Ramón Gaya y las ciudades)» (Trapiello, 2000: 11-27). Para otras obras pintadas en Italia véase Ramón Gaya. Obra reciente pintada en Roma (1991).
} 
El lenguaje se impregna de palabras italianas, se dice y escribe Firenze y Venezia en vez de Florencia y Venecia, y se juega con algunas palabras, tal y como hacen muchos de los españoles que viven allí; un ejemplo: la palabra hermano tiene un femenino diferente, fratello se vuelve sorella, en vez de usar el femenino en italiano, sorelle, pero para referirse a las hermanas Zambrano, convierte en femenino el masculino italiano y españoliza ese plural, fratellas, palabra absolutamente inexistente en italiano. Escribe desde Venecia, La Sereníssima, el 26 de mayo de 1958:

Queridísimas fratellas: Cuando llego aquí ya no sé despegarme. No es ya la belleza, indiscutible, de la ciudad lo que me embruja, sino el ritmo de la vida, el compás que tiene aquí, todavía, la vida. La ausencia de los coches (que son tan igualatorios, tan emborronadores de todo), hace que uno pueda oír ese compás. Yo no pido ya vivir-vivir (pues demasiado sé que para mí eso ha pasado) pero sí percibir su música... Y aquí, se percibe. Se percibe a pesar de los turistas, porque los turistas pueden ser molestos, inoportunos, pero no son corte, interrupción de la vida, como es, en cambio, todo lo mecánico (Zambrano-Gaya, 2018: 65).

El 29 de agosto le escribe Jorge Guillén, «al querido y admirado Ramón Gaya» para decirle que llega a Venecia el 11 de septiembre. La carta es un mensaje lanzado, como una botella, en medio del mar, pues desconoce si ha cambiado dirección: «le dirijo estas líneas como intento para restablecer el contacto» (Zambrano-Gaya, 2018: 67-68). No sabemos si se llegaron a ver en Venecia, pues la única alusión a Jorge Guillén en ese periodo es una carta a Tomás Segovia de diciembre, pero ya estaban ambos en Roma.

En esos días, Ramón se haya algo confuso por el fuerte encuentro emocional con su hija Alicia, con la que ha permanecido casi tres semanas, razón quizá por la que se muestra más desnudo ante la ciudad amada:

\footnotetext{
${ }_{10}$ En la correspondencia con Pedro Salinas, el gran amigo de Guillén, éste se da cuenta de la poca simpatía que Salinas le tenía al pintor: «Gaya ha venido estos días por casa a hacerme un dibujo. Como por lo visto soy muy poco fotogénico ha tardado tres días en hacer algo aceptable» (12 marzo 1928); «No sé quién la hace [Romance, revista], en realidad. Me huele a cierto mequetrefismo, del grupo Gaya» (5 marzo 1940); «Pero a pesar de todo eso y, lo más grave, de ser amigo de Ramoncicicito Gaya» (25 enero 1943); «Calvo me ha mandado un dibujo de Gaya, muy bien editado. Finísimo y atinado; ha cogido una expresión muy tuya, muy verdadera y la ha captado con delicadeza y sobriedad de líneas exquisitas. Lástima que sea tan majadero el dibujante. Pero ese favor le debemos» (24 febrero 1951). Mientras Jorge Guillén le había escrito antes: «Esta tarde volveré a ver a Gaya; pinta cosas finísimas» (2 noviembre 1950); «Gaya es para mí el mejor pintor de México [...]. A Gaya, muy aislado, y sin dinero -consecuencia de su pintura y de su independencia, y no solo de su carácter difícil- lo he encontrado mucho más razonable, digno y serio de lo que yo me figuraba a través de sus artículos. Claro que es, en definitiva, un esteta; de ahí su juanramonismo hasta el absurdo» (18 marzo 1951). Véase SalinasGuillén (1992: 84, 223, 302, 561, 544 y 562).
} 
El encuentro con Alicia me dejó atontado por algún tiempo; me encontré con una mujer muy mía, y al mismo tiempo... allá, lejos. No sé cómo explicarme; cuando se fue me dejó muchísimo más solo [de lo] que he podido estar, quizá, nunca, y... sin embargo casi no me entiendo con ella. Después de marcharse de París me costó mucho trabajo... nivelarme (Zambrano-Gaya, 2018: 70).

En esa misma carta a María Zambrano, escrita el 11 de septiembre desde La Sereníssima, expone sus sensaciones frente a las ciudades italianas

Querida María: No he muerto. Estoy aquí en la Sereníssima, como casi siempre que me pierdo. Desde Florencia, en donde me perdí también por unas semanas, os telefoneé..., en el vacio, y al repetir la llamada desde Venezia, con el mismo resultado [...] me di cuenta de que para mí, en París, cada día es un día menos, mientras que en otras partes, cada día (bueno o malo) lo siento como un día más. Así llegué a Firenze (no, no temas, no voy a recitar el Tenorio), y la encontré preciosa pero ahogada en el calor, ese calor que yo no soporto, que me anula, que me borra: La Sereníssima, pues, y aquí estoy aún, porque ya sabes lo que me pasa con esta ciudad, que cada día es más hermosa y ... otra. Ahora, aligerada de tedeschi [alemanes, para aludir a los turistas], con las primeras nubes de un otoño suavísimo, me tiene atontolinado (Zambrano-Gaya, 2018: 70-71).

María comprende que se pierda en Venecia, es un lugar adecuado para ello. A ella misma no le gusta Roma, «no me encuentro en ella». Atenta a la diferencia de carácter de ambos («Yo me excedo en la palabra; tú, en el silencio» (Zambrano-Gaya, 2018: 76). Filosófica es la respuesta de María, respecto a la relación con su hija Alicia («pero esas extremas situaciones y sentires, no lo tomes como consuelo, purifican; es lo que más purifica, y por tanto fortifica») y respecto a los países mediterráneos:

He visto algunas cosas claras en este tiempo. Por ejemplo: que los italianos se pierden en la belleza o en la práctica -los romanos esto último, sobre todo-. Que los griegos no se perdieron en la belleza y, sin embargo, solo el amor los salvaba. Que los italianos no se pierden jamás en el amor y por él se han salvado: Dante, sus Santos: Francisco, Catalina y otros menores (Zambrano-Gaya, 2018: 75).

De esa estancia en Venecia se conserva otra carta del 25 de septiembre, desde La Sereníssima, a Salvatore. Se resiste a irse, pero el dinero se acaba y no queda más remedio que volver a su estudio de Roma:

Salvatore: me da vergüenza seguir aquí, un día y otro; pero cuando llego a esta ciudad no sé cuándo saldré de ella, pues desde luego algo me sucede aquí, y después de haberlo dicho muchas veces (aunque un poco de dientes afuera), voy pensando seriamente 
en una especie de embrujo o filtro envenenado. La cuestión es que he visto pasar por aquí (sucederse) los festivales, los congresos, las «mostras» (exposiciones), y yo... impertérrito. Ahora sí, ya no puedo quedarme más, me quedé sin un «soldo» [dinero], y solo metiéndome en mi estudio de Roma, puedo rehacerme un tantico (Gaya, 2016: 555-556).

La ciudad que debe abandonar presenta su belleza en cualquiera de los más sencillos momentos: «Estoy sentado en un café frente a San Giorgio il Maggiore, en donde atardece (sobre la fachada del Palladio) y... no digo más» (Gaya, 2016: 557). Disfruta de los conciertos de Vivaldi y Stravinsky; de este último escuchó por la calle los ensayos, pues el concierto era en la sala grande de la Scuola di San Rocco, con entradas carísimas y traje de etiqueta.

En Roma, en diciembre, vería a Jorge Guillén. Ramón tiene en las Zambrano dos auténticas hermanas, a las que ve todas las semanas, pero a veces le cansa su problemática situación económica y vital, los constantes lamentos. E1 8 de diciembre de 1958 le escribe María que, con toda probabilidad, le responde a una petición de Ramón para ver a Elena:

Ramón: He hablado con Elena. Me ha dicho que, con mucho gusto, y que si no me telefonea en contra -tenía que avisar a Carini- mañana martes 9 vendrá a mi casa a las 9 de la noche o 9-1/4.

En mejor, me parece, que tú vengas también. Ven antes, cuando quieras (Zambrano-Gaya, 2018: 79).

En cierta manera, da la sensación de que Gaya se encuentra entre el deseo de silencio, de la quietud para pintar, del aislamiento ordenado, y, por otra parte, la necesidad de establecer relaciones para encontrar compradores de sus cuadros y editores para sus artículos, lo cual perturba el ritmo tan imprescindible para realizar su obra. El 16 de enero de 1959, escribe Gaya a Salvador Moreno: «Elena se ha empeñado en presentarme a media Italia y estoy lleno de compromisos» (Gaya, 2016: 561). No parece que se conocieran desde hacía mucho tiempo, pues el 29 de mayo le escribe María: «Mas te debo decir que ahora es Elena quien se quedará encargada de la cuestión, y es persona, como viste, seria» (Zambrano-Gaya, 2018: 89).

Elena Croce suele interesarse también por argumentos que comparte con María Zambrano, la historia y presencia de las religiones, de ahí que asistan a su casa Elémire Zolla, Cristina Campo, Ernesto de Martino:

Y, por último, que el lunes a las nueve y media estamos invitados en casa de Elena donde irán varias gentes, entre otras, una que mucho me hubiera interesado conocer: Ernesto de Martino, historiador de las Religiones y Etnógrafo... una de las poquísimas que aquí me 
hubiera gustado conocer. Y desde hace años he hecho lo posible; ahora sin decir palabra ¡voilà! (Zambrano-Gaya, 2018: 89-90).

Al año siguiente, en 1960, Gaya publica en italiano cuatro ensayos de $E l$ sentimiento de la pintura, para Quaderni di Pensiero e di Poesia, de De Luca editore, de Roma, con traducción de Leonardo Cammarano. El tres de mayo María le informa que sus ensayos han sido bien acogidos: «Parece ser que aquí ha habido algunas reacciones favorables y Elena me habló de dos personas de muchísima exigencia que se quedaron muy pasmados con tus ensayos» (Zambrano-Gaya, 2018: 142). No es descabellado pensar que una de esas personas debió ser Cristina Campo, pseudónimo de Vittoria Guerrini, la otra podría ser el escritor Pietro Citati, que escribió sobre el libro, o bien el compañero de Cristina, el historiador de las religiones Elémire Zolla.

Cristina-Vittoria queda impresionada por la fuerza del escritor-pintor. A su antiguo compañero, traductor y profesor de filología germánica, Leone Traverso, le escribe en junio de aquel mismo año para compararlo con una de sus guías espirituales, Simone Weil:

Gaya es de la misma raza. Dice cosas todavía más extremas, si eso es posible. Es realmente el loco del pueblo, el enano de Velázquez o el de Shakespeare, a los únicos que se les permite decir la verdad. Después de la muerte de Pasternak, descubrir a Gaya me ha sido un gran consuelo. Léelo, te lo ruego. Espero que tú también escribas sobre él. Es uno de esos libros, de esos hombres, que entran en nuestras vidas de golpe, y se quedan. (Aquí, gracias a Dios, escapan todos con solo nombrarlo: es el escándalo del día) (Campo, 2007: 108).

Ese mismo mes, el 14, Tomaso Carini, el compañero de Elena Croce, le escribe a Gaya para anunciarle que el 25 de junio, a las 18.30, Cristina Campo hablará en la radio italiana sobre su libro Il sentimento della pittura y (utiliza el auténtico nombre de Cristina) «Vittoria Guerrini (Piazza Lauro de Bosis 6, Roma) desea enormemente releer el libro en español» (Zambrano-Gaya, 2018: 151). Para Cristina «Nos encontramos en ese lugar misterioso que es el cruce de lo temporal con lo eterno, el perfecto cumplimiento en el perfecto desaparecer. En este lugar (opuesto al histórico, que intenta continuamente guiarnos en el tiempo) se sitúa un crítico que es también un artista: el pintor español Ramón Gaya» (Campo, 2008: 13). Y añade:

Pero para el artista puro la creación no es más que obediencia, respuesta a esa realidad que quiere ser salvada, llegar a transparentarse a través de él, es decir, a través de un alma desnuda [...]. El libro entero es, por lo demás, una sucesión de toques fulminantes, carente de un sistema aparente, un conjunto de aproximaciones fulgurantes y de precisas hipérboles, un 
diario sellado y clarísimo, escrito en una lengua que es no obstante (y no es esto su encanto menor) prisionera de la misma expresividad que con cada palabra deshace (Campo, 2008: $14,16)^{11}$.

El 26 de mayo le había escrito a Leone Traverso sobre el texto: «Lo que llevé conmigo era demasiado largo. Lo daré al "Approdo", junto con otra, sobre el estupendo ensayo de Ramón Gaya Il sentimento della pittura, un librito de pocas páginas que quisiera que tú leyeras, si te es posible» (Campo, 2007: 107). El 14 de agosto Cristina le confiesa de nuevo que ya «tengo un artículo sobre Ramón Gaya» (Campo, 2007: 109). Y el 11 de mayo del año siguiente le vuelve a preguntar: «¿Escribirás sobre Gaya?» (Campo, 2007: 113).

El que sí escribió el 28 de mayo de 1960 en la Gazzetta del Popolo de Turín fue su compañero Elémire Zolla, con el título «La pintura y la nada». El 6 de junio María le envía una copia («Ramón, ahí va el artículo de il Zolla. Es bastante bueno, plantea bien el asunto y creo te hace visible. Aunque te lo hayan mandado ellos, te lo mando yo por si lo necesitas» (Zambrano-Gaya, 2018: 146). En el artículo Zolla afirma: «No conozco la pintura de Gaya, pero su libro tiene valor autónomo»; y añade:

Es este de Gaya un breviario de purificación de todo prejuicio, que debiera capacitar al artista a abandonarse a su destino sin dejarse deformar por el peso de esta maraña polémica que de día en día resulta más total. Se trata de un breviario que puede parecer [...] casi un desvarío sublime, o lo que es lo mismo, un arrojarse al vacío, un zarpar hacia un mar desconocido. Pero, precisamente, esto es el Arte (Zolla, 1995: 73-75).

El conocido escritor Pietro Citati escribe, el 18 de junio de 1960, el artículo $I$ quaderni di pensiero e di poesia, donde muestra su fascinación por nuestro pintor:

Pero Gaya es sobre todo un escritor; y posee un temperamento y un estro, rarísimos de encontrar entre los ensayistas de arte actuales. Ardiente, luminosa, su inteligencia se excita por sí misma, transformando en desesperados dramas sus propios hallazgos intelectuales. Mente sistemática, y a la vez arbitraria y fantástica, junta luces y sombras [...]. Devoto de San Juan de la Cruz, del vacío, y del silencio de la realidad, no pierde nunca ocasión de soltar un bon mot o un aforismo (Citati, 1995: 158-159).

Dos años más tarde Cristina le regalará a Ramón Gaya su libro Fiaba e mistero (Florencia, Vallecchi editore, 1962) con la siguiente dedicatoria: «A Ramón Gaya / per gratitudine / Cristina Campo / Natale '62».

\footnotetext{
${ }^{11}$ Archivo Ramón Gaya, no recogido en las obras conocidas de Cristina Campo, aunque parece que fue publicado en 1960. Recogido en el catálogo Ramón Gaya. Antología 1948-1999 (2008).
} 
De 1960 es el artículo de Gaya «Estatuas y esculturas», referidas a las del Imperio Romano, donde resalta el contenido social y público de las primeras:

Las estatuas quieren, sobre todo, «estar», estar muy a la vista de todos, dejarse ver, presumir, lucir, pues son «públicas» y es fatal en ellas mucha insolencia y una especie de petulancia marmórea. El mármol, el barro, la piedra, la cera, el bronce de la escultura, en cambio, quisieran «permanecer» lo indispensable, lo irremediable, lo preciso, y luego irse hacia dentro, hacia el centro de sí mismos, y allí, con la ayuda del alma, poderse transfigurar, es decir, «resucitar» (2018: 227).

$\mathrm{Su}$ interés por las estatuas/esculturas le lleva a detenerse en la plaza de la basílica de San Antonio de Padua, «muy confusa, muy borrosa», ante la escultura del condottiero Gatamelatta realizada por Donatello, una de las primeras esculturas ecuestres del Renacimiento. Aunque de esa ciudad le interesa más, lógicamente, la Capilla de los Scrovegni pintada por el Giotto: «Esas pinturas, convertidas ahora en vida real ellas también, o mejor, vueltas de nuevo a ser vida real, parecían irrumpir en nuestro mundo y borrar de un manotazo esa orgullosa y desalmada frontera que se acostumbra a poner entre la vida y la creación», para añadir luego: «Me sentí atacado por la realidad de todas aquellas figuras a las que conocía linealmente, plásticamente, pero de las que había ignorado hasta entonces toda su energía y todo su poder» (2018: 221-223).

La visita a Vicenza, ciudad con fuerte presencia de la obra de Palladio, le permite reflexionar sobre la clasicidad y la modernidad, teniendo como referencia a Goethe que no cree que buscase en Palladio «lo Antiguo -lo antiguo convertido en fantasma que vuelve- sino en modernidad vigorosa, firme, que abarcara también lo antiguo» (2018: 228). Viendo el palacio Chiericati, se da cuenta «de que no era repetición, insistencia académica, "regusto" de la Antigüedad, sino continuación fluida, correlativa; era sencillamente lo Moderno, lo único que puede ser lo moderno: dependencia legítima de lo antiguo, subordinación libre y natural a lo antiguo, a lo anterior» (2018: 230).

En realidad, el Goethe autor de Las penas del joven Werther y colaborador del manifiesto del Sturm und Drang, va a Italia, llegando hasta la lejana Sicilia, en busca de la cultura grecolatina. Siguiendo las huellas de Winckelmann, busca lo antiguo. Gaya diferencia lo antiguo de lo clásico. Clásico es «lo antiguo verdadero», que permanece porque «lo rejuvenecemos constantemente nosotros con nuestra precipitada e irreflexiva vejez hacía delante» (2018: 231); por eso se da cuenta «de que moderno no podía querer decir nada si no quería decir simplemente vivo [...]. El vaivén del arte artístico, construido, ejercido, no me interesaba, y el arte que me interesaba no era... arte, sino vida» (2018: 244-245). 
Coincide aquí con el poeta italiano Dino Campana (1885-1932), autor de Canti Orfici, que, aunque atraído por la Naturaleza, vuelve a Italia desde Argentina -como Ramón lo hará desde México- porque necesita los Museos, el hacer de los antiguos, y desconfía de la vanguardia que rechaza lo clásico porque sin los grandes autores del pasado no se puede construir el futuro.

En aquel mes de agosto de 1960 Ramón disfruta de la compañía de su hija en Barcelona. Elena Croce es su punto de referencia en Italia para la difusión de su obra. El 3 de agosto le escribe a María, mostrando su desinterés por volver a América:

Sí, dile a Elena que yo volveré a Roma sin falta, antes de un posible viaje a México, y que pienso luchar por no tener que volver a las Américas; París, si fuera necesario. (Entre paréntesis te diré que tengo una gran nostalgia de Roma, y más que de ella misma, de lo italiano, mucho más soportable que lo nuestro) (Zambrano-Gaya, 2018: 153).

Ramón hace de intermediario para que su amigo Carmelo Pastor le enviase al amigo y poeta Tomás Segovia un libro de Ungaretti (Zambrano-Gaya, 2018: 159). El 9 de marzo de 1961 Pastor le comunica las dudas de Elena sobre si su estancia en España se prolongará más de lo previsto: «Anteayer hice un arroz (creo, tan bueno como el último que Ud. probó) dedicado a Elena Croce y Tomaso (sic) Carini. Piensan mucho en Ud. y se preguntan si "il soggiorno andaluzo non si prolong[h] erà oltre il previsto"» (Zambrano-Gaya, 2018: 160). Y el 15 de junio, Tomaso Carini, compañero de Elena Croce, le anuncia con total discreción, la posibilidad de venta de uno de sus cuadros: «¿Cuándo vuelve a Roma? Aquí, el Banco de Italia desearía adquirir una obra suya, pero creo que no tengo nada adecuado entre sus cosas ni debo inmiscuirme en esto» (Zambrano-Gaya, 2018: 163-164).

En 1956 Ignazio Silone y Nicola Chiaromonte, conocidos de Ramón, habían fundado la revista de arte y política Tempo presente, donde publicaría también María Zambrano su «Lettera sull'esilio» (n. ${ }^{\circ} 6,1961$, páginas 405-410). Escribe María a Ramón irónicamente: «La "Carta sobre el exilio" tuvo una excepcional acogida. Lo deben de haber leído lo menos cinco o seis personas; una de ellas, Silone, la quiso publicar inmediatamente en Tempo presente, y ya aquí creo la deben de haber leído por lo menos, dos, quizá tres» (Zambrano-Gaya, 2018: 167).

Las diversas amigas asocian Venecia a Ramón: María Zambrano escribe el 3 de agosto del 1961: «Esta mañana me la he encontrado [a Araceli] delante de tu cuadro [El hijo pródigo] diciendo, con una voz que me recordó a aquella con la que gritaba asomada a la ventana del [hotel] Bonvecchiati en Venezia, que Venezia era lo más bello del mundo; gritando, sí: "esto es pintura, esto es pintura, esto es ser un pintor”» (Zambrano-Gaya, 2018: 166-167). Y el 12 de septiembre de 1962 la amiga 
Alba Buitoni Gatteschi, conocida por ser la fundadora de los Amigos de la Música de Perusa, no puede no relacionar su visita a Venecia con el amigo Ramón Gaya. A él le manda una postal con la Visitazione de Tintoretto, de la Scuola di San Rocco: «Querido Ramón, se me ha revelado por completo la luz de Venezia y pido perdón al creador por mi mezquindad. Pienso mucho estos días en usted y su espíritu está conmigo» (Zambrano-Gaya, 2018: 170).

Ese año Ramón publica en Il Mondo, revista que apoyaba la llamada «tercera vía», posición laica y liberal alejada del Partido Comunista Italiano y de la Democracia Cristiana: el 5 de junio de 1962 (XIV, 23, página 15), «Diario di un pittore - Bellezza e modernità»; el 31 de julio, «Diario di un pittore - Nella cappella di Giotto» (XIV, 31, páginas 15-16); el 25 de septiembre, «Diario di un pittore - Statue morte» (XIV,3 9 , página16).

Las afueras de Roma, con la Via Appia y los campos de los alrededores, atraen la mirada del pintor. Sin embargo, parece atraerle más Venecia o Florencia. Desde esta última ciudad le escribe a María el 22 de octubre de 1962: «El campo, con los tostados otoñales está increíble de hermoso; en cuanto se sale de Roma se reconcilia uno con Italia, y no sé porque nos empeñamos en vivir ahí; ¿de qué ventajas goza uno, ni qué mundo intelectual visita uno, ni qué posibilidades... tipográficas disfruta uno?» (Zambrano-Gaya, 2018: 174).

Ramón taciturno, introvertido, contrariamente a escritores como Rafael Alberti, que llegaría en 1963 y escribiría Roma, peligro para caminantes, inmerso en un mundo cultural respaldado por el PCI (Partido Comunista Italiano), apenas si visita el círculo de amigos de Elena Croce. Antonio Sánchez Barbudo, el 7 de octubre de 1962, cuenta a Salvador Moreno que Ramón «nos presentó gente por allá, a la Croce y otros» (Zambrano-Gaya, 2018:173). En junio de 1965 Elena se queja a María de que Ramón está ilocalizable: «No veo nunca a Ramón, las antiguas discrepancias están olvidadas, pero no tengo tiempo de buscarlo siete veces al teléfono» (CroceZambrano, 2015: 61). Ramón estaría siempre presente en el epistolario de las dos amigas aunque, como llega a decir Elena, «no ha escrito nunca» (Croce-Zambrano, 2015: 114).

Alba Buitoni le escribe el 20 de mayo de 1963 desde Madrid con el fuerte impacto causado por la contemplación de Las Meninas: "Querido Ramón: Todo es extraordinario, desconcertante. Pero Las Meninas nos han hecho llorar con estremecida alegría. El cuadro más hermoso, más poético, más humano, más triste del mundo» (Zambrano-Gaya, 2018: 176).

Fue precisamente Elena y su círculo de sus amigos lo que animaron a Gaya a presentarse al premio Inedito, fundado por la escritora Serena Foglia. Lo recibió ex 
aequo con Mauro Senesi en Milán ${ }^{12}$. Aunque el premio incluía la edición no llegaría a publicarse. Serena le escribe el 16 de diciembre de 1965, aunque él ya estaba al tanto, tal y como veremos en la carta que escribió a Grau diez días antes:

Estimado señor Gaya tengo el placer de comunicarle que el jurado ha decidido concederle, exaequo con Mauro Senesi, el premio Inedito (250.000 liras cada uno) por su ensayo sobre Velázquez.

Como tal vez sepa hemos decidido emprender la publicación de las obras premiadas.

Estaríamos encantados con contar con usted en la sencilla ceremonia de la entrega del premio que tendrá lugar en Milán a mediados del mes de diciembre (Zambrano-Gaya, 2018:189).

La concesión del premio a Ramón Gaya provocó un cierto escándalo, pues Ramón no cumplía los requisitos: debía ser una obra en italiano y de tema actual. Veamos cómo lo cuenta el propio Gaya el 6 de diciembre a Marina y Julián Grau Santos, pintor:

Acaban de darme un premio por el ensayo de Velázquez que empecé a escribir en España (pues mi prestigio aquí es, en realidad de escritor), no sin cierto escándalo, pues acudí al concurso empujado por la [Elena] Croce y sin estar, ni mínimamente, dentro de la ley, es decir, de las bases, pues se pedía un escrito sobre un tema de actualidad italiana y, claro, escrito en italiano, mientras que yo presenté un ensayo sobre Velázquez, y ... jen español!, pues no hubo ni tiempo de traducirlo. La comunicación del jurado viene a decir que «pese a estar completamente fuera de las bases, se premia por la fuerza y belleza estilísticas, y por la originalidad y profundidad del contenido». Pero ya podéis imaginar las protestas de los concursantes (Gaya, 2016: 628-629).

El 12 de diciembre de 1966 Elena y Tomaso Carini le comunican que se han cambiado de casa, Piazza Cairoli, 6: «Elena y yo nos hemos cambiado de casa; estamos ahora en el centro y tenemos apartamentos más agradables que los que usted ha conocido» (Zambrano-Gaya, 2018: 193), y esperan que su exposición vaya bien.

El 30 de julio de 1969 Elena le cuenta a María el proyecto del Comité para ayudar a intelectuales exiliados, fundado por ella, de alojarles en la Villa delle Ginestre [Villa de las retamas], propiedad de la Università di Napoli Federigo II, el edificio donde había vivido al final de sus días Giacomo Leopardi, con Antonio Ranieri, cerca de Pompeya, en Torre del Greco, y que posteriormente había acogido a insignes literatos y estudiosos:

\footnotetext{
${ }^{12}$ En 1975 recibió este premio Antonio Tabucchi por su primera novela, Piazza d'Italia.
} 
[Al Comité, con Presidente honorario el escritor Ignazio Silone] le habían ofrecido la villa Ranieri (de la Retama) donde vivió los últimos años Leopardi. Es una casita meridional muy modesta, alrededor había hace tiempo un terreno estupendo ahora descuidado (no hablemos de los estragos hechos en las zonas del Vesubio, entre las más hermosas de Italia), antigua, que podría ser restaurada rápidamente (también para esto tenemos seguros) porque la Universidad de Nápoles la ha dejado abandonada. El aire es maravilloso, hay un trenecillo, creo, que cada media hora te lleva a Nápoles en media hora (Croce-Zambrano, 2015: 113114).

Elena Croce le escribe a María Zambrano sobre la visita que ha hecho Ramón en agosto de 1969:

Sabes que está aquí Ramón, está bien, y por ahora no tiene preocupaciones económicas perentorias, está contento por la felicidad de su hija, por ser abuelo de hermosos niños. Ha preguntado mucho por vosotras. Está un poco apagado porque quiere concentrar todas sus energías en el trabajo para recuperar el tiempo perdido [...]. No siente curiosidad por casi nada ni por nadie, y todos acaban sintiéndose culpables por su culpa, por no esforzarse lo suficiente (Croce-Zambrano, 2015: 119).

María le cuenta a Ramón lo de la Villa meses más tarde, el 19 de noviembre:

Hemos hablado de lo hermoso que sería que tuvieras tu habitación allí, en la Villa delle Ginestre. No me atrevo casi a pensar que vamos a vivir allí. Elena tiene genialidad, inspiración, es alguien. Y aunque no se logre se lo agradeceré in aeternum. Mas... ¿por qué no, por qué no vamos a ir? Y si fueras tú, si allí tuvieras un nido...

Sabes bien que nuestra compañía no es de las que quitan la soledad al pájaro (ZambranoGaya, 2018: 212).

Las líneas finales son una alusión al principal ensayo de Ramón, Velázquez, pájaro solitario, pero también, y especialmente, al poema leopardiano Il pájaro solitario, nombre del pájaro Monticola solitarius; referencia animal con el que se identificaba el poeta italiano, pues está siempre solo y se dedica a cantar. En este caso referido al Gaya pintor y crítico, que se podría dedicar a pintar y a escribir sin que nadie le quitase su soledad.

En 1970, Gaya compra un pequeño estudio en Roma, en el callejón Vicolo del Giglio, n. ${ }^{\circ}$ 2, que conservará siempre. Algunos meses antes, el 21 de junio, Elena Croce le escribía a María: «Ramón (ique solo frecuenta a Tom!) parece que se va a comprar una casita pequeñísima y demasiado cara... pero (entre nosotras) 
quizá sea mejor, si no dentro de poco estará como al principio» (Croce-Zambrano, 2015: 147). El 15 de julio María le responde: «Estoy contenta de que Ramón haya tomado posesión de su taller, esperemos que se sienta tranquilo para pintar» (CroceZambrano, 2015: 164). Mantiene contacto con Leonardo Cammarano, que traduce «Velázquez, pájaro solitario» («Velázquez passero solitario») para el número uno de la revista de Elémire Zolla, Conoscenza religiosa, (1971: 64-79), donde también publicaría Cristina Campo. Cammarano debate con Ramón sobre Matisse y sobre el arte figurativo. Escribe a Gaya el 1 de marzo de 1971:

Pero ¿"arte figurativo"? Sit venia verbo. En Italia no existen ni el arte, ni los críticos de arte, porque en su lugar existe el compromiso político del arte. Por lo tanto, Ciapski [Czpaski] constituye una eficaz antítesis irónica, porque es antimodernista (así como suena), y defensor de un arte decididamente inútil. O tempora o mores! ¡Estamos llegando a tener que defender la inutilidad! (Zambrano-Gaya, 2018: 216-217).

La presencia de Ramón en las cartas se va diluyendo. Él escribe menos y Elena confiesa el 15 de enero de 1972 que ya no le ve. Sin la presencia de la común amiga, María Zambrano, en Roma, la figura de Ramón se vuelve invisible.

En 1978 la revista Prospettive Settanta (abril-septiembre, año IV, n. ${ }^{\circ}$ 2-3) publicó una sección denominada "Omaggio a Ramón Gaya», donde aparecieron algunos textos del propio Ramón: Sonetti, Roccaforte spagnola, Pastora Imperio, Manolete y Osservazioni su Velázquez, y escribe el hispanista británico Nigel Dennis:

él no ha perseguido nunca la popularidad, no ha comprometido sus propias convicciones para conquistar una amplia aprobación [...]. Aunque, a primera vista, la variedad de actitudes creativas de Gaya (pintor, crítico, poeta) pudieran sugerir una personalidad artística fraccionada o dividida, hay una inconfundible unidad en su trabajo - una unidad de origen y finalidad. En su pintura y escritura él medita -implícita o explícitamente- sobre el misterio común del arte: sobre esos momentos de legitimidad absoluta, en disciplinas artísticas diferentes, en donde se alcanza una especie de comunión con ese misterio (Dennis, 1978: $49,51-52)$.

No quisiera terminar este trabajo sin referirme al volumen Ramón Gaya in Italia. Entre la variadas colaboraciones recogidas -además de las anteriormente citadas de Pietro Citati y Elémire Zolla-, encontramos las de Andrés Trapiello ( $G$ Gaya para italianos»), Leonardo Cammarano («Gaya: la elegancia del realismo») y Giorgio Agamben («En lugar del poema»), este último, conocidísimo filósofo hoy, en 1965 leyó 
su tesis en La Sapienza de Roma sobre Simone Weil ${ }^{13}$. Escribe Agamben, comentando el poema «Mansedumbre de obra»:

Lo que nos dice el soneto de Ramón Gaya es, entonces, que el dictado del poema, el límite último que en la obra es accesible a la experiencia, no es un saber o un conocer, sino una dimensión ética, el gesto más propio del hombre, su morada abismal entre viviente y lenguaje. Con la identificación del $\varepsilon \theta 0 \varsigma$ como lugar último del poema, también nuestra lectura debe llegar a su conclusión (Agamben, 1995: 31).

Para Andrés Trapiello, frente a los pintores excesivos y gesticulantes como Picasso, Gaya pertenece a otro grupo:

no solo en minoría, sino casi una excepción, amantes de la música callada de las cosas, de esa armonía tan rara que es todo lo que en uno hay de ruina, viajaron hasta Italia en busca de algo que en Italia está desnudo: la misma pintura, una idea de pintura incluso que entre nosotros han practicado «italiano»" como Velázquez, Rosales y ahora Ramón Gaya, nuestros más tizianescos pintores (Trapiello, 1995: 38).

Por otro lado, el que fuera el traductor italiano de Il sentimento della pittura (Roma, De Luca editore, 1960), Leonardo Camaranno, escribía: «He admirado a menudo de qué modo, con unos leves trazos y ciertas tonalidades sutiles, consigue identificar atmósferas complejas e instituir imprevistas "sinestesias" [...] ha elevado la delicadeza a norma de vida» (Cammarano, 1995: 51).

Italia, junto con México y España forman los pilares de su ser. Dejemos que sean las palabras de Ramón a Manuel Borrás y Arturo Ramoneda las que cierren este texto:

Italia me pareció un atrevimiento. El descaro de la realidad y de la belleza lo encontré en seguida en las plazas, en las fachadas, en los cuadros. Se me ofreció, de pronto, un concepto de belleza mucho más rico, más vivo, más cálido, más cercano. La belleza, desde ahora, no sería para mí aquel rostro rígido, frío, liso, terso, impecable, que me habían enseñado, obligado a admirar, y que siempre me pareció un rostro tan triste. La belleza era, ella también, sumamente impura, defectuosa, expuesta, en peligro; en una palabra, la belleza no era nada... ideal, sino algo muy real, muy corpóreo (Borrás-Ramoneda, 2007: 335).

\footnotetext{
${ }_{13}$ Agamben actuó como el apóstol Felipe, al igual que otros muchos escritores e intelectuales (Natalia Ginzburg, Alfonso Gatto, Enzio Siciliano...), en la película de Pasolini El evangelio según San Mateo.
} 


\section{Bibliografía}

AA.VV., Ramón Gaya in Italia, Murcia, Accademia di Spagna di Roma/CajaMurcia/ Ayuntamiento de Murcia/Tropa, 1995.

AA.VV., Ramón Gaya. Antología 1948-1999 (Catálogo), Murcia, Museo Ramón Gaya/Instituto Cervantes de Nápoles, 5 diciembre 2008-5 marzo 2009.

Agamben, Giorgio, «En lugar del poema», en AA.VV., Ramón Gaya in Italia, Murcia/Accademia di Spagna di Roma/CajaMurcia/Ayuntamiento de Murcia/ Tropa, trad. Tomás Segovia, 1995, págs. 21-31.

Aub, Elena, «Entrevista a Ramón Gaya», en De viva voz. Entrevistas (1977-1998), selección y presentación de Nigel Dennis, Valencia, Pre-Textos, 2007.

Bellonci, Maria, Come un racconto. Gli anni del Premio Strega, Milano, Arnoldo Mondadori Editore, 1971.

Borras, Manuel- Ramoneda, Antonio, «Entrevista a Ramón Gaya», en De viva voz. Entrevistas (1977-1998), selección y presentación de Nigel Dennis, Valencia, Pre-Textos, págs. 319-343 [extraído de Boletín de la Fundación Federico García Lorca, Madrid-Granada, 1992], 2007.

Cammarano, Leonardo, «Gaya: la elegancia del realismo», en AA.VV., Ramón Gaya in Italia, Murcia/Accademia di Spagna di Roma/CajaMurcia/Ayuntamiento de Murcia/Tropa, 1995, págs. 45-53.

Campo, Cristina, Caro Bul. Lettere a Leone Traverso (1953-1967), edición y nota de Margherita Pieracci Harwell, Milán, Adelphi, 2007 [traducción del autor].

Campo, Cristina, «Due saggi (Dos ensayos)», en AA.VV. Ramón Gaya. Antología 1948-1999 (Catálogo), Murcia/Museo Ramón Gaya/Instituto Cervantes de Nápoles, 5 diciembre 2008-5 marzo 2009, 2008, págs. 13-16 [trad. Isabel Verdejo].

Campo, Cristina, Se tu fossi qui. Lettere a Maria Zambrano 1961-1975, ed. M. Pertile, Milán, Archinto, 2009 [traducción del autor].

Campo, Cristina, Si estuvieses aqui. Cartas a María Zambrano, 1961-1975, ed. Maria Pertile, introd. Adele Ricciotti, trad. Juan Pérez Andrés, Ajuntament de l’Eliana/Nexofia/Libros electrónicos de La Torre del Virrey, 2014.

Citati, Pietro, «I quaderni di pensiero e di poesia», en AA.VV. Ramón Gaya in Italia, Accademia di Spagna di Roma/CajaMurcia/Ayuntamiento de Murcia/Tropa, 1995, págs. 158-159 [extraído de «Letteratura e arte», Il Punto - Il Giorno, 18 junio 1960, pág. 9].

Colinas, Antonio, Sobre María Zambrano. Misterios encendidos, Madrid, Siruela, 2019.

Croce, Elena y Zambrano, María, A presto, dunque, e a sempre. Lettere 1995-1990, Milán, RCS Libri/Archinto, 2015 [traducción del autor]. 
Da Venezia, Mario, «Il sentimento della pittura», en Il Gazzettino di Venezia, 22 junio, 1960.

De Stefano, Cristina, Vida secreta de Cristina Campo, Madrid, Editorial Trotta, 2020.

Dennis, Nigel, «Ramón Gaya: el taller de la soledad», Prospettive settanta, n. ${ }^{\circ}$ 2-3, abril-septiembre 1978, págs. 43-52 [traducción del autor].

Gaya, Ramón, «He pintado ese momento», $A B C$, en Zambrano, M., Gaya, R. (2018), Y asi nos entendimos Correspondencia, 23-04-1989, págs. 233-235

Gaya, Ramón, De viva voz. Entrevistas (1977-1998), selección y presentación de Nigel Dennis, Valencia, Pre-Textos, 2007.

Gaya, Ramón, Obra completa, ed. Nigel Dennis e Isabel Verdejo, Valencia-Madrid, Editorial Pre-Textos, 2010.

Gaya, Ramón, Cartas a sus amigos, prólogo de Andrés Trapiello, ed. Isabel Verdejo y Nigel Dennis, Valencia, Editorial Pre-Textos, 2016.

Ladrón de Guevara, Pedro Luis, «Cristina Campo y su tiempo», en De Stefano, C. Vida secreta de Cristina Campo, Madrid, Editorial Trotta, 2020, págs. 9-26.

Museo Ramón Gaya, Ramón Gaya. Obra reciente pintada en Roma (Casa Palarea. Murcia. 17 octubre/17 diciembre 1991), Ayuntamiento de Murcia/Novograf S.A, 1991.

Museo Ramón Gaya, Las casas del pintor. Estudios de Ramón Gaya (Murcia. 14 febrero/30 junio 2014), Ayuntamiento de Murcia/Novograf S.A, 2014.

Salinas, Pedro y Guillén, Jorge, Correspondencia (1923-1951), Barcelona, Tusquets, 1992.

Trapiello, Andrés, «Gaya para los italianos», en AA.VV, Ramón Gaya in Italia, Murcia/Accademia di Spagna di Roma/CajaMurcia/Ayuntamiento de Murcia/ Tropa, 1995 Trad. Silvia Serra, págs. 33-43 [ ].

Trapiello, Andrés, «Solo, pero no de espaldas (Ramón Gaya y las ciudades)», en AA.VV. Ramón Gaya. El pintor de las ciudades, Catálogo Exposición IVAM, Valencia, 1 mayo-2 julio 2000, págs. 11-27.

Valcárcel Pérez, Jose Luis, Ramón Gaya, La vida entrecortada, Murcia, Tres fronteras ediciones, 2010.

Zambrano, María, Cartas de la Pièce (Correspondencia con Agustín Andreu), ed. Agustín Andreu, Valencia, Editorial Pre-Textos/Universidad Politécnica de Valencia, 2002.

Zambrano, María y Gaya, Ramón, Y así nos entendimos Correspondencia 19491990), ed. Isabel Verdejo y Pedro Chacón, epílogo de Laura Mariateresa Durante, Valencia, Editorial Pre-Textos, 2018.

Zolla, Ellémire, «La Pittura ed il Nulla», en «Ramón Gaya. Del color y la palabra...», Revista Literaria Arrecife, n. ${ }^{\circ}$ 35-36, otoño 1995 [extraído de De La Pittura, Il Nulla (1960, mayo 28), Gazzetta del Popolo, Turín, págs. 3-75]. 
